University of Nebraska - Lincoln

DigitalCommons@University of Nebraska - Lincoln

2004

\title{
Collecting Spectral Data over Cropland Vegetation Using Machine- Positioning versus Hand-Positioning of the Sensor
}

\author{
Donald Rundquist \\ University of Nebraska - Lincoln, drundquist1@unl.edu \\ Richard L. Perk \\ University of Nebraska - Lincoln, rperk1@unl.edu \\ Bryan Leavitt \\ University of Nebraska-Lincoln, bleavitt4@unl.edu \\ Galina P. Keydan \\ University of Nebraska - Lincoln, gkeydan2@unl.edu \\ Anatoly A. Gitelson \\ University of Nebraska at Lincoln, agitelson2@unl.edu
}

Follow this and additional works at: https://digitalcommons.unl.edu/natrespapers

Part of the Natural Resources and Conservation Commons

Rundquist, Donald; Perk, Richard L.; Leavitt, Bryan; Keydan, Galina P.; and Gitelson, Anatoly A., "Collecting Spectral Data over Cropland Vegetation Using Machine-Positioning versus Hand-Positioning of the Sensor" (2004). Papers in Natural Resources. 289.

https://digitalcommons.unl.edu/natrespapers/289

This Article is brought to you for free and open access by the Natural Resources, School of at DigitalCommons@University of Nebraska - Lincoln. It has been accepted for inclusion in Papers in Natural Resources by an authorized administrator of DigitalCommons@University of Nebraska - Lincoln. 
Published in Computers and Electronics in Agriculture 43 (2004), pp. 173-178; doi: 10.1016/j. compag.2003.11.002. Copyright @ 2004 Elsevier. Used by permission.

Submitted July 27, 2003; revised October 24, 2003; accepted November 16, 2003.

\title{
Collecting Spectral Data over Cropland Vegetation Using Machine-Positioning versus Hand-Positioning of the Sensor
}

\author{
Donald Rundquist, Richard Perk, Bryan Leavitt, \\ Galina Keydan, and Anatoly Gitelson
}

Center for Advanced Land Management Information Technologies (CALMIT)

113 Nebraska Hall, University of Nebraska-Lincoln, Lincoln, Nebraska, USA

Corresponding author - D. Rundquist, email drundquist1@unl.edu

\begin{abstract}
The paper describes an all-terrain motorized platform for deploying sensors and compares data collected by means of that system with those collected by means of hand-held sensors. The results not only highlight the greater variability in spectra that can be expected when deploying field radiometers by hand but, more importantly, they quantify the difference. Researchers should be aware of the potential for diminishing the validity of findings based on reflectance spectra acquired by means of hand-held sensors.
\end{abstract}

Keywords: Spectroradiometer, Goliath working platform, Boom-mounted sensors

\section{Introduction}

In a review article dealing with the principles of field spectroscopy, Milton (1987) suggested several guidelines for collecting data in the field by means of a radiometer or spectroradiometer. Four of those suggestions are: (1) use a mast or tripod to ensure a fixed geometry between the sensor, the standard panel and the target if at all possible; (2) ensure that the sensor is at least $1 \mathrm{~m}$ (preferably $2 \mathrm{~m}$ ) above the upper surface of the target; (3) unless variations in reflectance factor with azimuth are being studied, be consistent in always orientating the sensor horizontal 


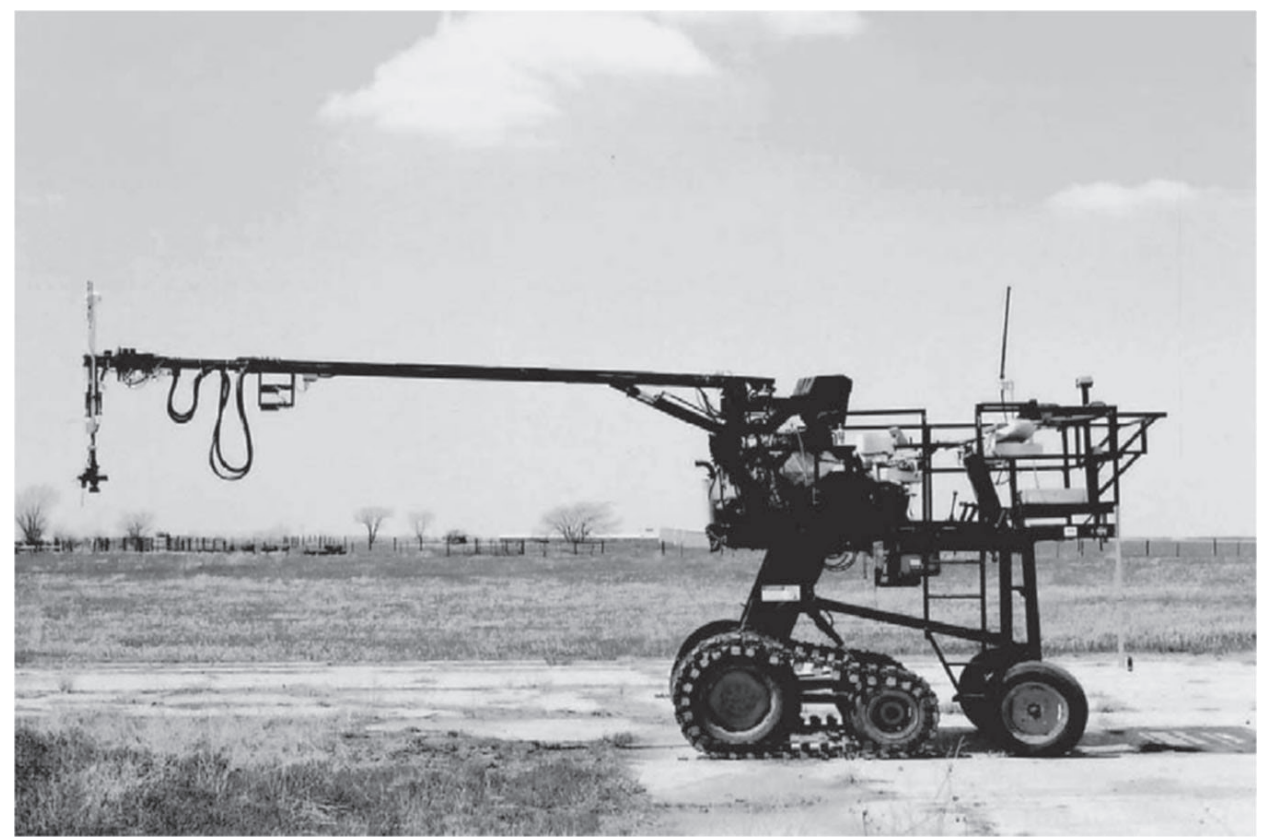

Figure 1. The Goliath platform.

support and positioning the other field equipment (including people) in the same positions relative to the Sun; and (4) operators should wear dark clothing and kneel some distance away from the target during measurements. The sum total of these selected recommendations is that there are inconsistencies and problems associated with a researcher physically holding and positioning a field radiometer during data collection. The solution, of course, is to deploy spectral-measurement equipment by means of a mast, tripod, or truck-mounted (or similar) boom. While it may be intuitively obvious that collecting spectral data with hand positioning is less systematic than positioning with a boom or similar, and therefore, the spectra may be more variable and less precise than those made using a mast or tripod, there is little or no information about the nature and/or quantitative extent of the difference.

Over the years, scientists have explored a variety of ways of deploying spectral-sensing and other similar devices in field settings. The approaches include holding the sensor with the human hand (e.g., Stark and Gitelson, 2000), attaching the instruments to hand-held masts (e.g., Price et al., 1993), or mounting them on a variety of motorized booms (e.g., Rundquist et al., 1995). Our instrument-deployment approach is focused on "Goliath," a motorized, all-terrain platform (Fig. 1) for positioning numerous types of scientific instruments (Rundquist et al., 2001).

The pertinent characteristics of the Goliath platform include a ground clearance of $1.91 \mathrm{~m}$, a width of $2.59 \mathrm{~m}$, and wheels positioned for movement through crops with $76.2 \mathrm{~cm}$ rows, a common width for row crops in Nebraska, USA. The tracked wheels allow access to difficult landscape positions and/or muddy fields. The working platform constructed on Goliath is $2.62 \mathrm{~m} \times 2.95 \mathrm{~m}$. It includes a seat for the driver along with four seats and desks for scientists and/or technicians. 
The hydraulic boom is $3.8 \mathrm{~m}$ long when stowed, but can be extended to 12 $\mathrm{m}$. It can be raised to a height of $10.5 \mathrm{~m}$, and rotated through $360^{\circ}$ around the platform. The boom can be lowered nearly to ground level to accommodate either sensor attachment/adjustments or calibration by means of a reference panel. The maximum sensor payload for the boom, at full extension, is $13.3 \mathrm{~kg}$. A metal frame at the end of the boom allows for easy attachment of sensors/instruments. It was fitted with small motors to facilitate movement of instruments, including from nadir to off-nadir positions.

Goliath allows one to easily address Milton's concern regarding fixed geometry, as the instrument position is repeatable from one sample site to the next. Once the boom height and viewing angle are set on the Goliath platform, the sensor-deployment configuration is rigid; thus, the field radiometer is oriented in exactly the same manner from one spectral sample to the next, across an entire field or study site. With regard to Milton's second concern, the hydraulic boom on Goliath can achieve a height of $10.5 \mathrm{~m}$ above the ground. The machine can obviously exceed the distance limitations experienced by a person attempting to hand-hold a sensor above a vegetation canopy. Again, once the vertical distance is set, it remains the same throughout a given data-collection campaign. Our approach in cropland vegetation, for example, is to maintain a consistent height above the canopy, and to collect the data from the nadir position. The hydraulic boom on Goliath can be rotated through $360^{\circ}$. Therefore, it is relatively easy to address Milton's third concern, and maintain the sensors in the principal plane of the sun, regardless of the orientation of the platform (e.g., with regard to the row directions in a field crop). Instruments are deployed via the Goliath boom; thus, there is no problem with people "contaminating" the spectral reflectance because of, for example, the color of one's clothing. The field researchers are stationed on the Goliath working platform, away from both the sensor and the target. Additionally, Goliath is painted flat-black.

The objective of our paper is to demonstrate quantitatively the differences one can expect when collecting spectral data using hand-held positioning of the sensor versus data collection with a machine-mounted sensor.

\section{Methods: Data Collection}

In an effort to examine the quantitative differences between spectra collected using the Goliath platform versus those obtained with hand-held instruments, measurements were made on July 3, 2001 in a large production field (64 ha) of corn (maize) using an Ocean Optics USB-2000 spectroradiometer (2,048 channels, 370$1,000 \mathrm{~nm})$. In the first instance, the fiber optic of the sensor was attached to an aluminum pole and positioned $3.6 \mathrm{~m}$ over a maize canopy $(1.97 \mathrm{~m}$ in height) by a person standing on a ladder. An attempt was made to hold the fiber optic of the Ocean Optics sensor at nadir and to orient the pole to the south. A total of six spectral samples were taken at each of eight locations in the field.

In the second experiment, the fiber optic of the same sensor (as used in the handheld mode) was attached to the boom of Goliath $3.6 \mathrm{~m}$ over the corn canopy. The fiber optic was positioned at nadir and the boom of Goliath was pointed south. Again, eight locations were sampled, with six spectra being acquired at each.

In both cases, a dual-fiber system, with two inter-calibrated Ocean Optics USB2000 radiometers, was used to collect radiometric data with a spectral reso- 
lution of about $1.5 \mathrm{~nm}$. Radiometer \#1, equipped with a $25^{\circ}$ field-of-view optical fiber was pointed downward to measure the radiance upwelling from the maize canopy $\left(L_{\lambda}^{\text {maize }}\right)$. Radiometer \#2, equipped with an optical fiber and cosine diffuser (yielding a hemispherical field-of-view), was pointed upward to simultaneously measure incident irradiance $\left(E_{\lambda}^{\text {inc }}\right)$. To match their transfer functions, the inter-calibration of the radiometers was accomplished by measuring the upwelling radiance $\left(L_{\lambda}{ }^{\mathrm{cal}}\right)$ of a white Spectralon (Labshere, Inc., North Sutton, New Hampshire) reflectance standard, simultaneously with incident irradiance $\left(E_{\lambda}{ }^{\mathrm{cal}}\right)$. Percent reflectance, $\rho_{\lambda}$ was computed as

$$
\rho_{\lambda}=\left(\frac{L_{\lambda}^{\text {maize }}}{E_{\lambda}^{\text {inc }}}\right)\left(\frac{E_{\lambda}^{\text {cal }}}{L_{\lambda}^{\text {cal }}}\right) \times 100 \times \rho_{\lambda}^{\text {cal }}
$$

where $\rho_{\lambda}^{\text {cal }}$ is the reflectance of the Spectralon panel linearly interpolated to match the band centers of each radiometer.

The dual-fiber approach results in fast measurement and minimal error due to variation in irradiation condition. One critical issue with regard to the dual-fiber approach is that the transfer functions of both radiometers must be identical. The Ocean Optics instruments were tested under laboratory conditions; over a $4 \mathrm{~h}$ period the standard deviations of the ratio of the two transfer functions did not exceed 0.004 .

Radiometric data were collected close to solar noon, and changes in solar zenith angle were minimal during the period of scanning. The two radiometers were inter-calibrated immediately before and immediately after measurement in each field.

\section{Results}

Figures 2A and B provide a summary of findings. Figure 2A contains the reflectance result for the hand-held radiometer and Figure $2 \mathrm{~B}$ for the Goliath-mounted radiometer. The insets in both graphics provide an enlarged view of the result for the visible spectrum $(400-700 \mathrm{~nm})$. As expected, reflectance in the visible range was quite low ( $<7 \%$ in all cases), with peak response in the green. In the case of the boom-mounted sensors, the range in reflectance for the visible region appears to be inconsequential ( $1 \%$ or less), but it is much more apparent (nearly $3 \%$ in the green spectrum) for the hand-held sensors. It is interesting to note that the reflectance (and variability) at the red chlorophyll absorption band (about $670 \mathrm{~nm}$ ) is quite similar in both instances.

Figures 2A and B also show that in the near-infrared (NIR) range, as expected, the overall reflectance is high ( $25 \%$ or greater). The range of reflectance in the NIR is only about $4 \%$ for boom-collected spectra, but is approximately $25 \%$ for the hand-collected spectra (the latter ranges from a low of about $25 \%$ to a high of about $50 \%$ ).

Standard deviations (SD) of reflectance were calculated for four of the handheld versus boom-mounted datasets. All of the SD of the hand-held measurements in the visible range were between 0.6 and $1.2 \%$. Thus, the coefficient of variation $(\mathrm{CV})$ was $12-18 \%$. However, the SD for the Goliath-collected visible spectra were only about $0.1-0.2 \%$, which corresponds to a CV below $4 \%$. For the NIR reflectance, the SD for the hand-held datasets range from about 4 to $10 \%$, 


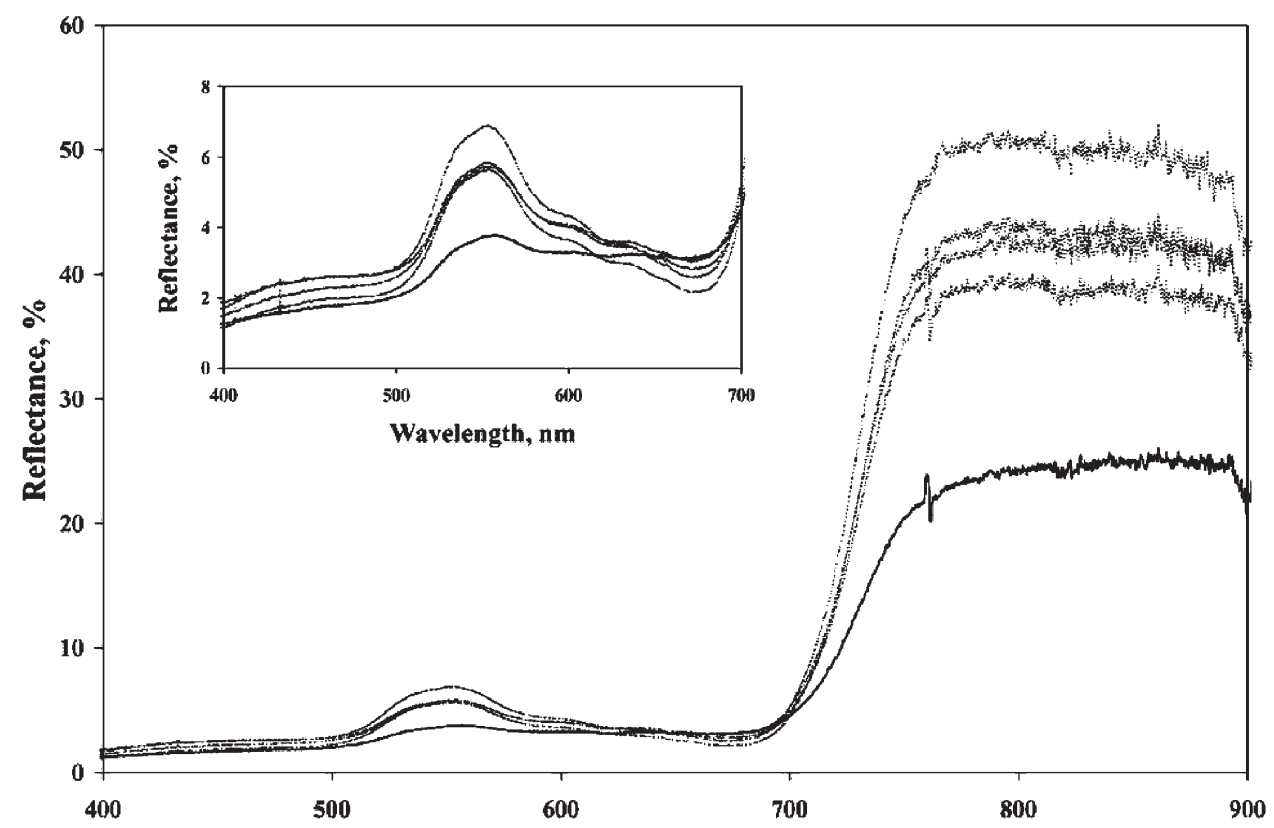

(A)

Wavelength, nm

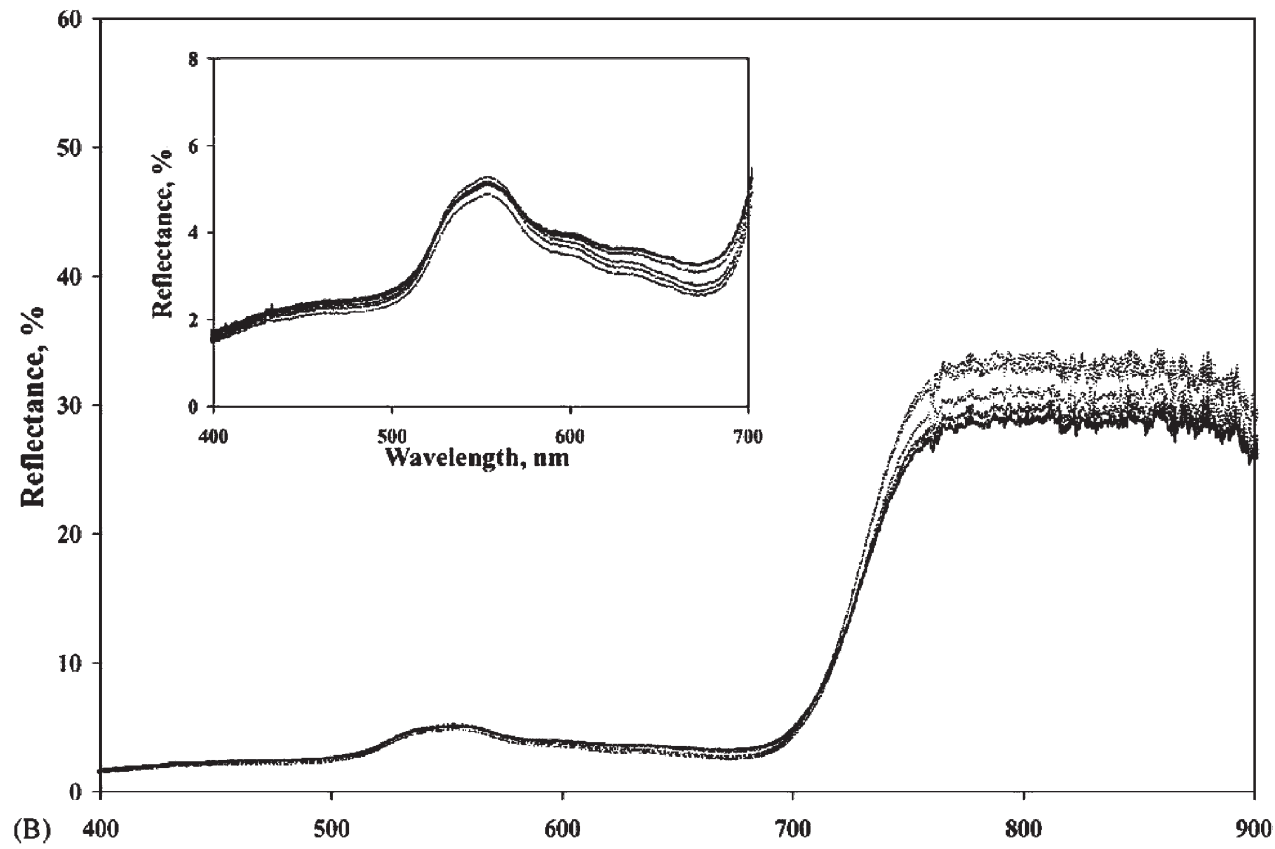

Figure 2. Summary of canopy reflectances acquired by (A) hand-held sensors and (B) boom-held sensors. 
while those for the boom-collected datasets were between 1 and $2 \%$. Thus, the CVs for the boom-collected datasets were 3-5\% in the NIR, but between 15 and $35 \%$ for the hand-held samples.

\section{Conclusion}

The Goliath platform allows for deployment of sensors in a controlled manner with repeatable positioning from place to place in a field, and systematic data collection. This approach minimizes the variance in spectra caused when sensors are deployed by hand. A pronounced quantitative difference between the two approaches was demonstrated. Results showed that when hand-held positioning of the sensor is used, one should expect a high variability in reflectance, and, as a result, error in estimating the biophysical characteristics of vegetation. Such error can prevent accurate estimation of vegetation status. The authors recommend that researchers avoid collecting spectral data in the field using hand-pointed instruments. Although most investigators will not have access to a stable platform, such as Goliath, field radiometers should, at the very least, be attached to a rigid mast and deployed in a consistent manner.

Acknowledgments - This paper is a contribution of the University of Nebraska Agricultural Research Division, Lincoln, Nebraska. Journal Series No. 14362. The research was supported in part by funds provided through the Hatch Act. The authors thank Jared Burkholder for assistance in data collection.

\section{References}

Milton, E., 1987. Principles of field spectroscopy. International Journal of Remote Sensing 8 (12): 1,807-1,827.

Price, K., Varner, V., Martinko, E., Rundquist, D., Peake, J., 1993. Symposium on the Influences of Land Management and Weather on Plant Biophysical and Hyperspectral Response Patterns of Tallgrass Prairies in Northeastern Kansas. Proceedings of the PECORA 12: 441-450.

Rundquist, D., Perk, R., Leavitt, B., Keydan, G., Smith, D., 2001. The “Goliath" data-collection and data-processing system for monitoring and analysis of cropland vegetation. Proceedings of The Third European Conference on Precision Agriculture: 295-300.

Rundquist, D., Schalles, J., Peake, J., 1995. The response of volume reflectance to manipulated algal concentrations above bright and dark bottoms at various depths in an experimental pool. GeoCarto International 10: 5-14.

Stark, R., Gitelson, A., 2000. Radiation regime in irrigated wheat. Proceedings of the Second International Conference on Geospatial Information in Agriculture and Forestry, pp. 89-96. 